\title{
Successful pregnancy soon after oral contraceptive-associated malignant hypertension
}

\author{
J. H. Silas* \\ M.D., M.R.C.P. \\ H. F. Woods* \\ D.Phil., F.R.C.P. \\ A. Singer $\dagger$ \\ D.Phil., M.R.C.O.G. \\ V. A. Brown†
M.R.C.O.G. \\ * University Department of Therapeutics, Hallamshire Hospital, Sheffield S10 2JF, and \\ $\dagger$ University Department of Obstetrics and Gynaecology, The Jessop Hospital for Women, Sheffield S3 $7 R E$
}

\begin{abstract}
Summary
A woman who developed malignant hypertension while taking a very low oestrogen oral contraceptive underwent an uncomplicated pregnancy conceived 3 months later. Her BP was well controlled with propranolol alone.
\end{abstract}

\section{Introduction}

Successful pregnancy after the development of malignant hypertension has been reported on 2 occasions (Kincaid-Smith, McMichael and Murphy, 1958; Weir and Willocks, 1976). In these patients conception occurred 4 and 3 years respectively after control of the malignant phase. The authors report a successful pregnancy in a patient who developed malignant hypertension while taking an oral contraceptive and who conceived 3 months later. Throughout pregnancy her BP was well controlled with propranolol.

\section{Case report}

A 21-year-old woman had taken Microgynon 30 (Schering) $(0.15 \mathrm{mg}$ levonorgestrel and $0.03 \mathrm{mg}$ ethinyloestradiol) for 3 years. She was admitted in June 1977 with a history of severe headache for one week and vomiting for one day. The BP was 230/170 $\mathrm{mmHg}$ and bilateral papilloedema, haemorrhages and soft exudates were seen on fundoscopy. Microscopic haematuria was present. Investigations revealed a creatinine clearance of $40 \mathrm{ml} / \mathrm{min}$ with a serum urea of $3.8 \mathrm{mmol} / 1$ and a serum potassium of $3.2 \mathrm{mmol} / \mathrm{l}$. The latter returned to normal following treatment. ECG showed left ventricular hypertrophy. IVP, isotope renogram, urinary VMA and catecholamine excretion were all normal.

The BP was initially controlled with i.v. diazoxide. Oral propranolol was started and the patient was discharged 3 weeks later taking propranolol $640 \mathrm{mg}$ daily. The dose of propranolol was increased to 960 mg following discharge and subsequent BP control was satisfactory. Two months after ward discharge her BP was $140 / 94 \mathrm{mmHg}$ (standing values quoted) and the fundi appeared normal apart from a few old exudates. The contraceptive pill was discontinued on admission to hospital.

Three months later the patient was found to be 9 weeks pregnant. She had been strongly advised to avoid pregnancy and some contraception had been organized. At this ante-natal visit her BP was $120 / 80 \mathrm{mmHg}$, fundoscopy normal, and creatinine clearance $103 \mathrm{ml} / \mathrm{min}$. During pregnancy her $B P$ was maintained between $110-143 / 75-80 \mathrm{mmHg}$ on a propranolol dose of $640 \mathrm{mg}$. Serum urea, urio acid, blood platelet count, and urinalysis for protein were normal throughout the pregnancy.

Fetal growth was monitored biochemically and by ultrasound. Serial urinary total oestrogens and plasma placental lactogen (HPL) remained within normal range until 38 weeks' gestation when the HPL fell to $3.4 \mathrm{mg} / \mathrm{l}$. A reduction in fetal growth as measured by serial cephalometry was initially noted at 34 weeks and continued over the following 4 weeks. During the 37th week a reduction in fetal activity was reported and the patient was immediately admitted to hospital. Cardiotacography (external) revealed a baseline fetal bradycardia of 100-115 beats/min but this rate responded by more than 20 beats/min on fetal movement. The maternal resting heart rate was between $56-64$ beats $/ \mathrm{min}$. In view of the reduction in fetal activity and objective evidence of fetal growth retardation, delivery was planned during the 38th week of gestation. Propranolol was stopped $36 \mathrm{hr}$ before delivery without loss of BP control. The fetal heart rate $24 \mathrm{hr}$ after propranolol had been stopped was $120-130$ beats/min. Vaginal examination revealed a grossly unfavourable cervix (Bishops score 2) for induction and delivery by elective Caesarean section under epidural anaesthesia was undertaken.

The delivered male infant was small for dates, weighed $2.6 \mathrm{~kg}$ (5th centile weight for gestation) and had an Apgar score of 9 and 10 at one and $5 \mathrm{~min}$. 
The cord venous blood pH was 7.34 and the base deficit $2 \cdot 1$. The placenta weighed $420 \mathrm{~g}$ and was histologically normal. The infant's blood sugar was $1.4 \mathrm{mmol} / \mathrm{l}$ at one $\mathrm{hr}$ increasing to $2.5 \mathrm{mmol} / \mathrm{l}$ after $2 \mathrm{hr}$. No abnormality of the infant was noted subsequently.

BP was elevated from the 3rd postoperative day (BP $140 / 110 \mathrm{mmHg}$ ) until it was treated 6 weeks later. Three months after delivery her BP was 120/90 $\mathrm{mmHg}$ and propranolol dosage $160 \mathrm{mg} /$ day.

\section{Discussion}

Malignant hypertension is a rare complication of the combined oral contraceptive steroids (Editorial, 1976). Both conjugated oestrogens and the combined oral contraceptive pill are known to cause elevation in BP and a causal link with oestrogens was inferred (Crane, Harris and Winsor, 1971). Although malignant hypertension has not been reported with a 30 $\mu \mathrm{g}$ oestrogen pill, the incidence of hypertension with such preparations may be greater than that with the $50 \mu \mathrm{g}$ oestrogenic combinations suggesting a progestogenic effect (Meade et al., 1977; Royal College of General Practitioners' Oral Contraceptive Study, 1977). In this patient, no other cause for hypertension was found and BP was surprisingly easy to control after the oral contraception was stopped; observations which suggest that this compound may have played a role in producing the malignant phase.

Poorly controlled hypertension and renal disease during pregnancy are associated with an increased risk to mother and fetus. Although there was some evidence of renal impairment at presentation, immediate antihypertensive therapy restored BP and renal function to normal and this contributed to the successful outcome of the gestation. Even so, the infant was small for dates.

There has been considerable doubt about the safety of $\beta$-blockers in hypertensive pregnancies. Intravenous administration of propranolol has been associated with neonatal hypoglycaemia and respiratory depression (Tunstall, 1969; Cottrill et al., 1977) and in a small retrospective study the use of propranolol was linked with an increased incidence of perinatal death (Lieberman et al., 1978). Prospective studies of the use of orally administered $\beta$-blockers do not support these fears (Turner, Oakley and Dixon, 1968; Eliahou et al., 1978; Tcherdakoff et al., 1978). In contrast, hypertensive pregnancies treated with oxprenolol were associated with a reversal of intrauterine growth retardation (Gallery et al., 1978). The present patient was receiving a larger dose of propranolol than has been previously documented, and there was no obvious adverse effect on the fetus. The transient fetal bradycardia detected on ante-partum cardiotacography was presumably related to the $\beta$-blocker. The bradycardia was reversed by fetal activity and disappeared soon after stopping the drug. Omission of propranolol for 4 days did not affect BP control, a feature recorded by Kristensen, Steiness and Weeks (1978). In retrospect, however, stopping the $\beta$ blocker before Caesarean section seems unnecessary.

It appears that a past history of malignant hypertension is not a contra-indication to pregnancy when renal function is good and the BP is well controlled.

\section{Acknowledgment}

We are very grateful to Dr L. E. Ramsay for his helpful comments.

\section{References}

Cottrill, C.M., McAllister, R.G., Gettes, L. \& Noonan, J.A. (1977) Propranolol therapy during pregnancy, labor and delivery. Journal of Pediatrics, 91, 812.

Crane, M.G., Harris, J.J. \& Winsor, W. (1971) Hypertension, oral contraceptive agents, and conjugated estrogens. Annals of Internal Medicine, 74, 13.

EDITORIAL (1976) The pill and raised blood pressure. British Medical Journal, 1, 58.

Eliahou, H.E., Silberberg, D.S., Reisin, E., Romem, I., Mashiach, S. \& Serr, D.M. (1978) Propranolol for the treatment of hypertension in pregnancy. British Journal of Obstetrics and Gynaecology, 85, 431.

Gallery, E.D.M., Saunders, D.M., Hunyor, S.N. \& GYORY, A.Z. (1978) Improvement in foetal growth with treatment of maternal hypertension in pregnancy. Clinical Science and Molecular Medicine, 55, 359s.

Kincaid-Smith, P., McMichael, J. \& Murphy, E.A. (1958) The clinical course and pathology of hypertension with papilledema (malignant hypertension). Quarterly Journal of Medicine, 27, 117.

Kristensen, B.Ø., Steiness, E. \& Weeks, J. (1978) Propranolol withdrawal and thyroid hormones in patients with essential hypertension. Clinical Pharmacology and Therapeutics, 23, 624.

Lieberman, B.A., Stirrat, G.M., Cohen, S.L., Beard, R.W. \& Pinker, G.D. (1978) The possible adverse effects of propranolol on the foetus in pregnancies complicated by severe hypertension. British Journal of Obstetrics and Gynaecology, 85, 431.

Meade, T.W., Chakrabart, R., Haines, A.P., Howarth, D.J., NORTH, W.R.S. \& STIRLING, Y. (1977) Haemostatic, lipid and blood-pressure profiles of women on oral contraceptives containing $50 \mu \mathrm{g}$ oestrogen. Lancet, ii, 948.

royal College of General Practitioners' Oral ConTRACEPTIVE STUDY (1977) Effect on hypertension and benign breast disease of progestogen component in combined oral contraceptives. Lancet, i, 624.

TCherdakoff, P.H., Colliard, M., Berrard, B., Kreft, C., Dupay, A. \& Bernallle, J.M. (1978) Propranolol in hypertension during pregnancy. British Medical Journal, 2,670 .

Tunstall, M.E. (1969) The effect of propranolol on the onset of breathing at birth. Annals of Anaesthesia, 41, 792.

Turner, G.M., OAKLeY, C.M. \& Dixon, N.G. (1968) Management of pregnancy complicated by hypertension obstructive cardiomyopathy. British Medical Journal, 4, 281.

WEIR, R.J. \& WILlocks, J. (1976) A successful pregnancy following malignant phase hypertension. British Journal of Obstetrics and Gynaecolog. $, 83,581$. 